\title{
JOURNAL.RU
}

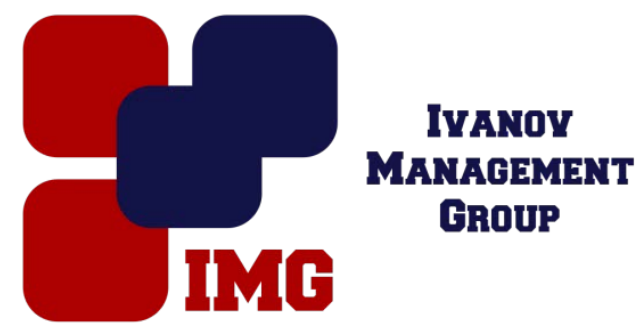

Спичак И.В. , Вареных Г.В., Белоусова А.

Белгородский государственный университет Белгород, Россия

doi: 10.18411/lj-31-10-2016-1-12

idsp 000001:lj-31-10-2016-1-12

\section{Медико-социальный портрет детей с нарушением веса (на примере г. Белгорода)}

По последним оценкам Всемирной организации здравоохранения (ВО3), более 1,9 миллиарда взрослых людей в возрасте 18 лет и старше имеют избыточный вес, из них свыше 600 миллионов страдают ожирением. Эта проблема актуальна даже для стран, в которых немалая часть населения постоянно голодает. Около $11,0 \%$ мужчин и $13,0 \%$ женщин страдают от ожирения, а $39 \%$ людей в возрасте 18 лет и старше имеют избыточный вес (38,0\% мужчин и 40,0\% женщин)[1].

Ожирением называют увеличение веса за счет жировой ткани: у мужчин более чем на $25,0 \%$, а у женщин - на $30,0 \%$, а у детей - обычно, если вес превышает 12,0\% идеального для данного возраста[3].

Повсеместно наблюдается рост частоты ожирения у детей и подростков. Ожирением в развитых странах страдают приблизительно $10 \%$ детей старшего возраста и 15,0\% подростков. Данные исследований свидетельствуют, что избыточную массу тела имеют около $12 \%$ российских детей, а ожирение - 8,5\% детей, проживающих в городах, и 5,5\% - в сельской местности. Почти у 60,0\% взрослых, страдающих ожирением, проблемы с лишним весом начались в детском и подростковом возрасте [2].

Точных сведений о распространённости гипотрофии в настоящее время нет, поскольку пациенты с лёгким и среднетяжёлым течением этого заболевания в большинстве случаев не регистрируются. Распространенность гипотрофии у 
детей в различных странах мира, в зависимости от уровня их социальноэкономического развития, колеблется от 2,0 - 7,0 до 30,0 \%. По данным Роспотребнадзора РФ 19,0\% детей и подростков имеют недостаточный вес, тяжёлая гипотрофия диагностируется примерно у 1,0-2,0\% детей.

В целях исследования на наличие проблем нарушения веса было проведен социологический опрос среди подростков школьного возраста 7, 8 и 11 классов г. Белгорода.

Материалы и методы исследования: 60 анкет школьников г. Белгорода в возрасте от 13 до 18 лет; при проведении исследования применялись следующие методы: анкетирование, структурный, графический, сегментационный, группировки, ранжирования, сравнения.

Результаты. Для реализации поставленной цели была разработана анкета социологического опроса для школьников 7,8 и 11 классов г. Белгорода.

В ходе анализа антропометрических данных было обнаружено, что нормальный вес наблюдался у 21,7\% опрошенных, такая же часть от всех респондентов оказалась с наличием избыточного веса. Стоит подчеркнуть, что лица с недостаточным весом составили 56,7\%.

В 7 классе сильно недостаточный вес (индекс массы тела (ИМТ) ниже 15,2-16,2) наблюдался у 5,0\% опрошенных (7,0\% мальчиков, среди девочек не обнаружено), недостаточный вес - у 50\% (у 42,6\% мальчиков и 66,7\% девочек), избыточный - 15,0\% (21,4\% мальчиков, среди девочек не обнаружено) и 20,0\% с ожирением (16,7\% девочек и 21,4\% мальчиков). Следует отметить, что количество школьников 7 класса с нормальным весом составляет всего лишь 5,0\% (16,7\% девочек, среди мальчиков не обнаружено).

В 8 классе сильно недостаточный вес (ИМТ ниже 16,1-17,0) наблюдается у 20,0\% лиц (21,4\% опрошенных девочек и 16,7\% мальчиков), недостаточный вес - у 25,0\% (21,4\% девочек и 33,3\% опрошенных мальчиков). Количество учащихся 8 класса с нормальным весом составляет 35,0\% (35,7\% девочек и $33,3 \%$ мальчиков), избыточным - 20,0\% (21,4\% девочек и 16,7\% мальчиков), но лиц с ожирением среди учащихся 8 класса не было обнаружено.

В 11 классе сильно недостаточный вес (ИМТ ниже 17,1-17,6) обнаруживается у 15,0\% опрошенных $(21,4 \%$ девушек, у юношей не обнаружен), недостаточный вес - 55,0\% (у 64,2\% девушек и 33,3\% юношей). 
Количество учащихся 11 класса с нормальным весом составляет 25,0\% (14,2\% девушек и 50\% юношей), избыточным - 5,0\% (16,7\% юношей, у девушек не обнаружено). Лиц с ожирением среди учащихся 11 класса не было обнаружено.

Анализируя удовлетворенность респондентов собственным весом, было выявлено, что среди опрошенных с остро недостаточным весом 75,0\% удовлетворены тем, сколько они весят и лишь 25\% желали бы набрать несколько килограмм. Школьники с недостаточным весом - 61,5\% удовлетворены своим весом и $38,5 \%$ опрошенных желают сбросить несколько, на их взгляд, лишних килограмм. Среди лиц с показателем ИМТ, находящимся в границах нормы, удовлетворены своим весом лишь 30,7\%, а снизить вес желают 69,3\% опрошенных. Но 66,7\% учащихся с лишним весом желали бы его снизить, и только $33,3 \%$ удовлетворены тем, сколько они весят. Также 75,0\% школьников с ожирением хотели бы избавится от данной проблемы, а 25,0\% не считают нужным снизить массу тела.

Стоить отметить, что в большей части тем, сколько они весят, недовольны девушки. Так, $36,8 \%$ с недостаточным и 100,0\% с нормальным весом желали бы снизить свой вес, а 59,0\% девушек удовлетворены своим недостаточным весом. Отмечено, что 25,0\% юношей с недостаточным и 20,0\% с нормальным ИМТ также желают потерять несколько килограмм, а 75,0\% молодых людей удовлетворены недостаточным весом.

Оценивая свой внешний вид при наличии нарушении в весе, 25,0\% опрошенных заявили, что чувствуют дискомфорт в общении со сверстниками (11,5\% среди юношей и 35,3\% среди девушек).Рассматривая каждую возрастную категорию, в частности, в 7 классе такой ответ дали 25,0\% опрошенных $(21,4 \%$ мальчиков и $33,3 \%$ девочек), в 8 классе - 30,0\% всех опрошенных (что составило $42,9 \%$ девочек, мальчиков в данной категории лиц не обнаружено), а в 11 классе - 20,0\% всех школьников (28,6\% девушек, юношей также не обнаружено в данной категории лиц). Остро ощущают актуальность проблемы избыточного веса 58,3\% опрошенных школьников (42,3\% юношей и 70,6\% девушек), а проблему недостаточного веса у подростков школьного возраста находят 40\% учащихся (34,6\% мальчиков и $44,1 \%$ девочек).

В ходе опроса на обнаружение возможных этиологических факторов нарушения веса $35,0 \%$ респондентов находят причину в несоответствии 
количества получаемых калорий с их сжиганием (30,8\% юношей и 38,2\% девушек), $11,7 \%$ - в замедленном обмене веществ. Лишь 8,3\% школьников находят генетическую предрасположенность одним из факторов нарушений в весе. При этом, 41,7\% школьников отмечают нарушения нормального веса у своих родителей, близких родственников, недостаточный вес отмечается только у 24,0\%. Из 76,0\% опрошенных, имеющих родственников с избыточным весом, 36,0\% находят причину в перенесенных/врожденных заболеваниях, которые могли бы в последствии привести к настоящей проблеме, 52,0\% считают основными факторами гиподинамию и высокую калорийность потребляемой пищи.

При анализе образа жизни и привычек семей школьников было выявлено, что 54,7\% опрошенных совместно с родителями проводят время в походах, играх на природе, прогулках, а 16,0\% отмечают, что широкие праздничные застолья являются одной из семейных традиций. Среди домашних 30,0\% допускают прием пищи в позднее время суток, перед сном; 45,0\% школьников признаются, что в детском возрасте родители заставляли их доедать всю поданную порцию при отсутствии голода, но только 6,7\% из них наблюдали наличие избыточного веса с самого детства.

По результатам исследования режима и рациона питания школьников оказалось, что преимущественное количество респондентов (55,0\%) принимает пищу 3 раза в день (34,6\% мальчиков и 47,0\% девочек). Двухразовое питание обнаружилось у 23,3\% опрошенных, один раз полноценно принимают пищу 6,7\% подростков, 15,0\% принимают основную пищу 4 раза в день и более. В состав ежедневного рациона у 71,7\% опрошенных школьников входят фрукты, овощи, кисло-молочные продукты, каши (61,5\% мальчиков и 79,4\% девочек), лишь 5,0\% отмечают редкое потребление продуктов данного перечня (19,2\% юношей). Среди опрошенных 21,7\% абсолютно исключили фаст-фуд из своего рациона (23,1\% мальчиков и 20,6\% девочек), 21,7\% позволяют себе 1-2 раза в неделю посетить рестораны быстрого питания (26,9\% мальчиков и 17,6\% девочек).

Девушки, в основном большинстве, включают в свой режим питания 2 перекуса (41,1\%), а юноши - один (34,6\%), а 19,2\% мальчиков и $11,8 \%$ девочек совсем исключают перекусы, что составляет $15,0 \%$ всех опрошенных. В 
качестве перекуса 42,8\% мальчиков и 36,7\% девушек предпочитают пирожки, пиццу, газированные напитки, шоколадные батончики (в 7 классе - 30,0\% и $50,0 \%$, в 8 классе $-66,7 \%$ и $30,8 \%$, в 11 классе - 40,0\% и 36,4\% соответственно).Только 57,2\% юношей и 63,3\% девушек выбрали бы фрукты, йогурты, негазированную воду (в 7 классе - 70,0\% и 50,0\%, в 8 классе $-33,3 \%$ и 69,2\%, в 11 классе - 60,0\% и 63,6\% соответственно).

В связи с высокой учебной нагрузкой в школе выяснилось, что в 7 классе $50,0 \%$ учащихся проводят время в малоподвижном состоянии (время на уроках, подготовка домашнего задания, поиск информации в Интернете) до 5 часов (по $50,0 \%$ мальчиков и девочек), $35,0 \%$ - до 7 часов в день (42,6\% мальчиков и $16,7 \%$ девочек) и $15,0 \%$ - более 7 часов в день (7,1\% мальчиков и $33,3 \%$ девочек). В 8 классе - 20,0\% опрошенных находятся в малоподвижном состоянии до 5 часов (33,3\% мальчиков и $14,3 \%$ девочек), 50,0\% - до 7 часов в день (16,7\% мальчиков и $64,3 \%$ девочек) и $30,0 \%$ - более 7 часов в день $(50,0 \%$ мальчиков и 21,4\% девочек). В 11 классе лишь 5,0\% опрошенных проводят до 5 часов в малоподвижном состоянии (16,7\% только юношей), 30,0\% - до 7 часов в день $(16,7 \%$ юношей и $14,3 \%$ девушек) и $80,0 \%$ - более 7 часов в сутки $(66,7 \%$ юношей и $85,7 \%$ девушек).

В результате анализа ответов респондентов было выяснено, что школьники все же стараются вести активный образ жизни и заниматься спортом: 76,9\% юношей посещают специальные секции (в 7 классе $-85,7 \%$, в 8 классе $66,7 \%$ в 11 классе - 66,7\%). К основной группе здоровья относятся 84,6\% опрошенных юношей, $11,5 \%$ - к подготовительной и 3,8\% - к специальной группам (в 7 классе - 92,9\% к основной и 7,1\% к подготовительной; в 8 классе $83,3 \%$ к основной группе, 16,7 к подготовительной; в 11 классе - 66,7\% к основной, и по 16,7\% к подготовительной и специальным группам).

Установлено, что 26,5\% девочек занимаются в спортивных секциях, 58,8\% стараются заниматься спортом в свободное время и также регулярно посещают занятия физической культуры в школе (в 7 классе - 100,0\%, в 8 классе - 71,4\%, в 11 классе - 92,6\%). К основной группе здоровья относятся 64,7\% опрошенных девушек и по 17,6\% к подготовительной и специальной группам (в 7 классе $50,0 \%$ к основной, $33,3 \%$ к подготовительной и $16,7 \%$ к специальной, в 8 классе 
$-57,1 \%$ к основной, $28,6 \%$ к подготовительной и 14,3\% к специальной, в 11 классе - 78,6\% к основной и 21,4\% к специальной группам).

На вопрос о личном отношении к диетам $28,3 \%$ школьников ответили, что соблюдают определенный режим питания с целью контроля веса $(23,1 \%$ мальчиков и $32,6 \%$ девочек: в 7 классе - 42,6\% мальчиков и $33,3 \%$ девочек, в 8 классе - только 35,7\% девочек, в 11 классе - 28,6\% девушек). 3,3\% всех опрошенных (5,9\% девушек) принимали препараты с целью контроля веса. За консультацией к специалисту-диетологу обращались лишь $11,7 \%$ опрошенных (15,4\% мальчика и $8,8 \%$ девочек.).

Исходя из вышеизложеного вытекают следующие выводы:

1. Современный подросток в $56,7 \%$ случаев имеет недостаточный вес, а в $21,7 \%$ - нормальный либо избыточный.

2. 25,0\% ребят школьного возраста стесняются своего внешнего вида при наличии нарушений веса.

3. Причину нарушения веса в несоответствии потребляемых калорий с их тратой находят $35,0 \%$ опрошенных.

4. У родителей и родственников $41,7 \%$ подростков наблюдается отклонение от нормы ИМТ.

5. Семьи 54,7\% респондентов ведут активный образ жизни.

6. Современный подросток, в основном большинстве, имеет рациональный и сбалансированный режим питания, комбинирует время занятий спортом (посещает секции и занятия на уроках физической культуры) и периоды сниженной активности (уроки в школе, подготовка домашнего задания, просмотр телевизора).

7. Только около четверти $(28,3 \%)$ школьников соблюдают особый режим питания с целью снизить вес. 


\section{Литература}

1. ВОЗ. Ожирение и избыточный вес. //Информационный бюллетень - №311. Январь, 2015 г.;

2. Дедов,И.И., Мельниченко,Г.А.,Бутрова,С.А. Ожирение у подростков в России // Терапевтический архив. - 2007.-N 10.-С.28-32;

3. Родионова, Т.И., Тепаева, А.И. Ожирение - глобальная проблема современного общества // Фундаментальные исследования. - 2012. - № 121. - C. 132-136. 